\title{
Effects of virtual reality combined with balance training on upper limb function, balance, and activities of daily living in persons with acute stroke: a preliminary study
}

\author{
Min-Jae Jeon $^{\mathrm{a}, \dagger}$, Jong-Hoon Moon ${ }^{\mathrm{a}, \dagger}$, Hwi-young Cho ${ }^{\mathrm{b}}$ \\ ${ }^{a}$ Department of Healthcare and Public Health Research, National Rehabilitation Research Institute, National Rehabilitation Center, Seoul, \\ Republic of Korea \\ ${ }^{b}$ Department of Physical Therapy, College of Health Science, Gachon University, Incheon, Republic of Korea
}

Objective: The aim of this preliminary study was to investigate the effects of virtual reality combined with balance training on upper limb function, balance, and activities of daily living (ADL) in persons with acute stroke.

Design: Randomized controlled trial.

Methods: Fourteen acute stroke survivors were recruited and randomly assigned into two groups: the experimental group ( $\mathrm{n}=7$ ) and the control group $(\mathrm{n}=7)$. Both groups performed the conventional rehabilitation therapy for 30 minutes a day, 5 times a week, for 4 weeks. Additionally, the experimental group conducted the virtual reality training for 30 minutes on an unstable surface during each session, whereas the control group performed balance training for 30 minutes on a stable surface. All measurements were performed before and one day after intervention. Upper limb function, balance, and ADL were assessed using the Manual Function Test (MFT), the Berg Balance Scale (BBS), and the Korean version of the Modified Barthel Index (K-MBI), respectively.

Results: Both groups showed significant improvements in MFT, BBS, K-MBI after intervention $(p<0.05)$. There were no significant differences between the experimental and control groups with respect to MFT, BBS, and K-MBI after intervention. The experimental group showed a greater decrease in fall risk $(\mathrm{BBS}<45)$ after intervention than the control group $(p<0.05)$.

Conclusions: These findings suggest that virtual reality combined with balance training has a better effect on balance improvement than virtual reality training alone in persons with acute stroke.

Key Words: Activities of daily living, Postural balance, Stroke, Upper extremity, Virtual reality

\section{Introduction}

In Korea, the number of disabled individuals with cerebrovascular disease is increasing every year due to Westernized eating habits, lack of exercise, and increased number of elderly people [1]. Because post-stroke symptoms can be accompanied by severe sequelae, ongoing management of physical disability is important. Management of stroke victims is necessary from the outset, and reducing the risk of falls during hospitalization is an important preventive meas- ure to reduce secondary damage [2,3].

Decreases in upper and lower extremity function after stroke limit the performance of activities, such as self-care and locomotion [4]. The reduction in weight shifting control of the affected side after stroke causes considerable difficulty in maintaining balance. This deterioration of postural control ability is related to impairment of linkages between motor, sensory, and cognitive function [5], which affects the mobility of stroke survivors [6]. Balance is essential for the performance of activities of daily living (ADL) such as

Received: 11 November, 2019 Revised: 29 November, 2019 Accepted: 2 December, 2019

Corresponding author: Hwi-young Cho (ORCID https://orcid.org/0000-0003-0465-9665)

Department of Physical Therapy, College of Health Science, Gachon University, 191 Hambangmoe-ro, Yeonsu-gu, Incheon 21936, Republic of Korea Tel: 82-32-820-4560 Fax: 82-32-820-4420 E-mail: hwiyoung@gachon.ac.kr

These two authors contributed equally to this work as co-first author.

(c) This is an Open-Access article distributed under the terms of the Creative Commons Attribution Non-Commercial License (http://creativecommons.org/licenses/ by-nc/4.0) which permits unrestricted non-commercial use, distribution, and reproduction in any medium, provided the original work is properly cited.

Copyright $\odot 2019$ Korean Academy of Physical Therapy Rehabilitation Science 
dressing, toileting, and walking, and sufficient balance function is one of the predictors of performing independent ADL [7].

Balance control ability in humans is related to the width of the base of support and the center of gravity. Changes in the base of support require modulation of the sensory and motor systems [8]. Balance training on an unstable surface was positively reported to improve proprioception, which includes sensory and motor function in persons with stroke [9]. Performing activities on unstable surfaces brings about biomechanical changes in the trunk and core muscles [10]. According to a previous study with stroke survivors, balance training condition using unstable surface showed significantly more improvement in the Berg Balance Scale (BBS) and 10 meter walk test compared to stable surface condition [11]. However, this study used non virtual-reality tasks for interventions. Therefore, there is difficult to verify the effects of virtual reality training according to the different surface conditions.

Intervention methods for balance improvement in stroke survivors include visual feedback [12], imagery training [13], robot-assisted gait training [14], muscle strength training [15], whole-body vibration training [16], electrical nerve stimulation [17], and virtual reality [18]. Virtual reality training is often used to rehabilitate stroke survivors who have limited physical activity or cannot complete leisure activities in a real environment due to limited environmental and physical disability. Virtual reality training has the advantage of providing autonomy by presenting opportunities for independent exploration while providing stability in a virtual environment [19]. Virtual reality training can stimulate interest through visual and auditory feedback, while providing prompt feedback on task performance. Additionally, actively performing tasks can increase rehabilitative motivation [20].

Previous studies on virtual reality training have repeatedly reported on tasks related to balance enhancement [18, $21,22]$. These studies have examined virtual reality games [21], virtual reality-based rehabilitation training programs [18], and balance training using virtual reality [22]. However, research on the improvement of stroke survivors remain unclear when using an unstable surface while performing virtual reality training related to ADL. Therefore, it is necessary to investigate whether the improvement in persons with stroke is due to task training related to ADL or is due to virtual reality training focused on improving balance while on an unstable surface. According to Chen's meta-analysis [23], the effect of virtual reality training on persons with acute stroke was unclear. Therefore, the purpose of the present preliminary study was to examine the effects of virtual reality combined with balance training on upper limb function, balance, and ADL in acute stroke survivors.

Thus, present study hypothesized the following: virtual reality training focused on ADL performed on unstable surfaces would increase the upper limb function, balance, and ADL of patients with acute stroke compared to virtual reality training focused on ADL on a stable surface.

\section{Methods}

\section{Subjects}

This study included 14 persons with acute stroke. The inclusion criteria were as follows: (1) clinically diagnosed stroke, (2) stroke occurred within the last 30 days before the onset, (3) a score of 24 or more on the Korean Mini-Mental Status Examination, and (4) a stable medical condition. The exclusion criteria were as follows: (1) a history of visual or hearing impairment and (2) a history of orthopedic surgery. All participants voluntarily agreed to participate in the study and gave written consent. The study is approved by Institutional Review Board of Gachon University (IRB No. 1044396201708-HR-136-01).

\section{Procedures}

All participants who were selected in consideration of inclusion and exclusion criteria were randomly assigned to the experimental group $(n=7)$ or the control group $(n=7)$. After assignment, pre-evaluation was performed. Both groups performed conventional rehabilitation therapy for $30 \mathrm{mi}-$ nutes a day, 5 times per week, for 4 weeks, for a total of 20 sessions. Conventional rehabilitation therapy involved receiving physical therapy and occupational therapy. Physical therapy consisted of stretching exercises, gait training, and strengthening exercises, and occupational therapy involved performing purposeful activities, range of motion exercises, and task-based activities.

Additionally, the experimental group received 30 minutes of virtual reality training per training session on an unstable surface, whereas the control group additionally performed balance training for 30 minutes on stable surface. Upper limb function, balance, and ADL were evaluated. Post-evaluation was performed within 1 day after the completion of all interventions. All measurements were performed under the blinded condition. 

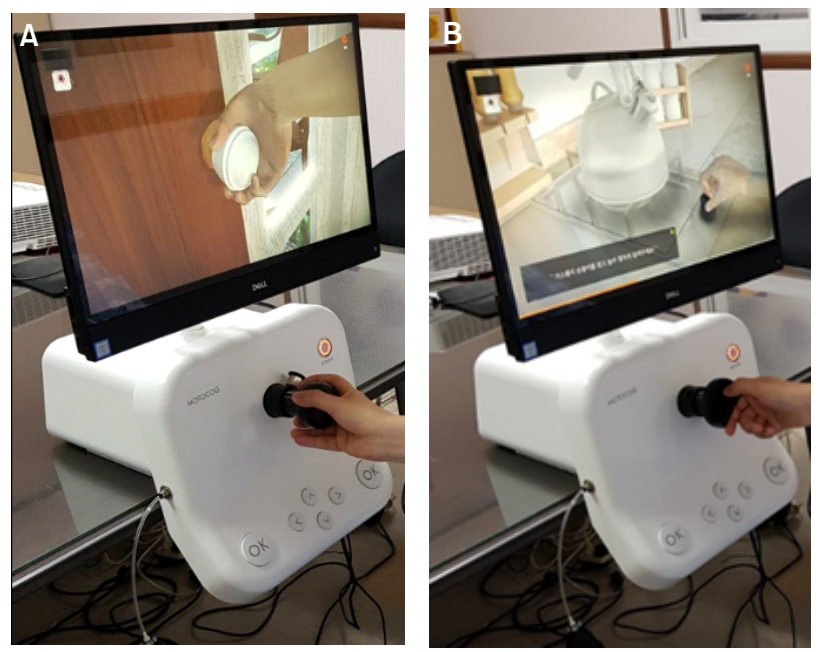

Figure 1. The subjects performed virtual reality training with Moto Cog rehabilitation program. (A) Opening a door lock. (B) Turning on a gas stove.

\section{Intervention}

The two groups performed virtual reality combined with balance training. Moto Cog (Cybermedic, Iksan, Korea) was used for the virtual reality rehabilitation program. This virtual reality program was developed to promote ADL. Moto Cog includes 3 training courses: hand function, cognition, and ADL (Figure 1). In this study, only the hand function and ADL courses were performed. The hand function course consisted of a door lock, turning on a gas stove, squeezing, and hammering. The ADL course involved performing ADL-related activities such as washing, cooking, and bathing. The difficulty level of training in all courses was divided into five levels from level 1 being very easy to level 5 being very difficult. The therapist explained the virtual reality training method to the subject and provided sufficient rest for fatigue during training. Specific virtual reality activities were chosen by the participants.

To improve balance, only the experimental group performed virtual reality training on unstable surfaces. The unstable surface used was a balance pad (AIREX, Anaheim, CA, USA). If necessary, a walker was used to prevent falls during training to ensure safety, and the therapist provided cues to maintain correct posture.

Subjects in the control group conducted balance training on over-ground. Balance training consisted of static standing, standing on one leg with eyes open, standing on one leg with eyes closed, and performed simple ADLs such as washing, cooking, and bathing.

\section{Outcome measurement}

\section{Upper limb function}

The Manual Function Test (MFT) was used to measure upper limb function. MFT is a tool for evaluating gross and fine motor abilities of the upper limbs and can be scored from a minimum of 0 to a maximum of 32 points. This test consists of 8 items. Sub-items are divided as follows: 4 items related to the upper extremity motion, 2 items related to grasp and pinch, and 2 items related to manipulative activities. The higher the score, the better the upper limb function. The inter-tester and intra-tester reliability of the MFT are both $\mathrm{r}=0.95$ [24].

\section{Balance}

The BBS is a dynamic balance test that scores functional tasks. The evaluation consists of 14 items. Each item is scored from 0 to 4 points according to the examiner's observations, for a total of 56 points. The score is based on the subject's ability to perform specific tasks as well as their ability to balance and maintain balance over a period of time. Since the evaluation of balance ability is performed together with functional tasks, information on balance ability as well as function can be provided. The higher the score, the better the balance. A person with a score below 45 points is considered to have an increased risk of falling [25]. The inter-rater reliability of the instrument was 0.98 , and the test retest reliability was 0.99 [26].

\section{Activities of daily living}

The Korean version of the Modified Barthel Index (K-MBI) was used to assess the subject's ADL [27]. The $\mathrm{K}-\mathrm{MBI}$ measures function in a total of 10 areas: personal hygiene, bathing, feeding, toileting, stair climbing, dressing, bowel control, bladder control, ambulation, wheelchair, chair/bed transfer. The K-MBI total score is assigned a minimum of 0 and a maximum of 100 points. The higher the score, the more independent the patient is in completing ADL. In the K-MBI, the locomotion domain includes stair climbing, ambulation, and transfers (chair/bed). The total score of the locomotion domain is a minimum of 0 to a maximum of 40 points. The inter-tester and intra-tester reliability of this index is $0.93-0.98$ and $0.87-1.00$, respectively [27].

\section{Statistical analysis}

The collected data were analyzed using IBM SPSS Statis- 
tics for Windows, Version 22.0 (IBM Co., Armonk, NY, USA). The one sample Kolmogorov-Smirnov test was used to confirm the normal distribution of the data. The group differences in general characteristics, upper limb function, balance, and ADL were analyzed using the chi-squared test or Mann-Whitney U-test. The Wilcoxon-signed rank test was used to compare before and after intervention changes between both groups. The level of statistical significance level was set 0.05 .

\section{Results}

General characteristics of upper limb function, balance, and ADL

Table 1 and Table 2 show the MFT, BBS, and K-MBI of the subjects. There were no significant differences between the two groups in MFT, BBS, and K-MBI before intervention $(p>0.05)$.

Table 1. General characteristics

$(\mathrm{N}=14)$

\begin{tabular}{lccc}
\hline \multicolumn{1}{c}{ Characteristics } & $\begin{array}{c}\text { Experimental } \\
\text { group }(\mathrm{n}=7)\end{array}$ & $\begin{array}{c}\text { Control } \\
\text { group }(\mathrm{n}=7)\end{array}$ & $p$-value \\
\hline Age (y) & $54.14(7.20)$ & $53.71(10.98)$ & 0.797 \\
Height (cm) & $165.57(10.10)$ & $163.71(11.54)$ & 0.898 \\
Weight (kg) & $65.29(9.60)$ & $63.86(8.43)$ & 0.653 \\
Sex (male/female) & $4 / 3$ & $3 / 4$ & 0.593 \\
Etiology (infarction/ & $6 / 1$ & $5 / 2$ & 0.515 \\
$\quad$ hemorrhage) & & & \\
Lesion side (right/left) & $4 / 3$ & $4 / 3$ & 1.000 \\
Onset period (d) & $9.86(7.71)$ & $8.14(2.97)$ & 0.949 \\
K-MMSE (score) & $27.14(2.27)$ & $27.00(2.31)$ & 0.948 \\
\hline
\end{tabular}

Values are presented as mean (SD) or number only. K-MMSE: Korean-Mini Mental State Examination.
Changes of upper limb function, balance, and ADL within groups

Table 3 shows the changes of MFT, BBS, and K-MBI. Both the groups showed significant improvements in MFT, BBS, and K-MBI (all assessments) after intervention ( $p<$ 0.05).

Comparisons between upper limb function, balance, and $A D L$ in two groups

Table 4 shows the change score of MFT, BBS, and K-MBI after intervention. There was no significant difference in the change of MFT, BBS, and K-MBI between both groups ( $p>$ $0.05)$.

\section{Changes of fall risk in two groups}

Table 5 shows the change of fall risk ratio $(\mathrm{BBS}<45)$ before and after intervention. The experimental group showed a greater decrease in fall risk ratio after intervention than the control group.

Table 2. Comparison between upper limb function, balance, and ADL before intervention $(\mathrm{N}=14)$

\begin{tabular}{llll}
\hline \multicolumn{1}{c}{ Variable } & $\begin{array}{c}\text { Experimental } \\
\text { group }(\mathrm{n}=7)\end{array}$ & $\begin{array}{c}\text { Control } \\
\text { group }(\mathrm{n}=7)\end{array}$ & $p$-value \\
\hline $\begin{array}{l}\text { Upper limb function } \\
\text { MFT (affected side) } \\
\text { (score) }\end{array}$ & $14.00(8.72)$ & $16.14(7.56)$ & 0.609 \\
$\begin{array}{l}\text { Balance } \\
\text { BBS (score) }\end{array}$ & $40.57(9.76)$ & $40.86(8.93)$ & 0.898 \\
ADL & & & \\
$\quad$ K-MBI total (score) & $65.86(11.87)$ & $68.86(16.14)$ & 0.749 \\
$\quad$ Locomotion (score) & $20.00(5.94)$ & $21.57(8.66)$ & 0.745 \\
\hline
\end{tabular}

Values are presented as mean (SD).

ADL: activities of daily living, MFT: Manual Function Test, BBS: Berg Balance Scale, K-MBI: Korean version of the Modified Barthel Index.

Table 3. Changes of upper limb function, balance, and ADL within groups

$(\mathrm{N}=14)$

\begin{tabular}{|c|c|c|c|c|c|c|}
\hline \multirow{2}{*}{ Variable } & \multicolumn{2}{|c|}{ Experimental group $(\mathrm{n}=7)$} & \multirow{2}{*}{ Z } & \multicolumn{2}{|c|}{ Control group $(n=7)$} & \multirow{2}{*}{ Z } \\
\hline & Pre & Post & & Pre & Post & \\
\hline MFT (affected side) (score) & $14.00(8.72)$ & $49.38(16.95)$ & $-2.366^{*}$ & $16.14(7.56)$ & $48.13(22.64)$ & $-2.371 *$ \\
\hline BBS (score) & $40.57(9.76)$ & $73.50(9.80)$ & $-2.366^{*}$ & $40.86(8.93)$ & $75.00(11.30)$ & $-2.384^{*}$ \\
\hline K-MBI total (score) & $65.86(11.87)$ & $79.13(19.03)$ & $-2.371^{*}$ & $68.86(16.14)$ & $81.25(18.81)$ & $-2.366^{*}$ \\
\hline Locomotion (score) & $20.00(5.94)$ & $12.75(4.17)$ & $-2.371^{*}$ & $21.57(8.66)$ & $12.88(3.18)$ & $-2.375^{*}$ \\
\hline
\end{tabular}

Values are presented as mean (SD).

ADL: activities of daily living, MFT: Manual Function Test, BBS: Berg Balance Scale, K-MBI: Korean version of the Modified Barthel Index. ${ }^{*} p<0.05$. 
Table 4. Comparison of change score of upper limb function, balance, and ADL in two groups $\quad(\mathrm{N}=14)$

\begin{tabular}{lrrr}
\hline \multirow{2}{*}{ Variable } & \multicolumn{2}{c}{ Change score } & \\
\cline { 2 - 3 } & $\begin{array}{l}\text { Experimental } \\
\text { group }(\mathrm{n}=7)\end{array}$ & $\begin{array}{c}\text { Control } \\
\text { group }(\mathrm{n}=7)\end{array}$ & \\
\hline MFT (affected side) (score) & $6.57(5.65)$ & $5.43(3.31)$ & 0.949 \\
BBS (score) & $6.57(3.41)$ & $3.71(2.63)$ & 0.092 \\
K-MBI total (score) & $18.43(8.38)$ & $14.86(9.26)$ & 0.249 \\
Locomotion (score) & $11.14(3.34)$ & $8.14(6.74)$ & 0.198 \\
\hline
\end{tabular}

Values are presented as mean (SD).

ADL: activities of daily living, MFT: Manual Function Test, BBS: Berg Balance Scale, K-MBI: Korean version of the Modified Barthel Index.

\section{Discussion}

The results of our preliminary study revealed that ADLfocused virtual reality training on an unstable surface is more effective for improving upper limb function, balance, and ADL for persons with acute stroke than that on a stable surface. Both the experimental and control groups showed significant improvement in all assessments after intervention, and there were no significant differences in all assessments between the two groups. There was no statistically significant change, but the experimental group showed a greater decrease in fall risk after intervention than the control group. This result suggests that ADL-focused virtual reality combined with balance training can enhance balance ability compared to that without balance training.

On an unstable surface, standing maintenance and weight shifting can improve balancing ability by increasing activation of the gastrocnemius muscles [28], biceps femoris muscles [29], and trunk muscles [10]. In the meta-analysis of French et al. [30], repetitive task training improved walking, ADL, and global motor function, but did not demonstrate improvement in lower limb functional activity or standing balance. We suggest that the repetitive tasks associated with ADL can be performed on an unstable surface, which can have a positive effect on improving the balance of stroke survivors.

Balance ability and ADL performance are closely related. In particular, basic ADLs, such as bathing, moving, and toileting, require adequate balance [31]. Insufficient balancing ability leads to falls, which can lead to severe secondary damage [7]. In the K-MBI, locomotion ability was measured in three areas: stair climbing, ambulation, and transfer (chair/ bed) [32,33]. There was no difference in locomotion be-
Table 5. Changes of fall risk ratio in two groups $(\mathrm{N}=14)$

\begin{tabular}{cccccc}
\hline \multirow{2}{*}{ Variable } & \multicolumn{2}{l}{ Experimental group $(\mathrm{n}=7)$} & & \multicolumn{2}{c}{ Control group $(\mathrm{n}=7)$} \\
& Pre & Post & & Pre & Post \\
\hline BBS & & & & \\
$\quad<$ score 45 & $5(71.4)$ & $2(28.6)$ & & $5(71.4)$ & $4(57.1)$ \\
$\quad \geq$ score 45 & $2(28.6)$ & $5(71.4)$ & & $2(28.6)$ & $3(42.9)$ \\
\hline
\end{tabular}

Values are presented as $\mathrm{n}(\%)$.

BBS: Berg Balance Scale.

tween the two groups. However, in future studies, it will be necessary to investigate whether the improvement of balance through virtual reality training combined with balance training affects locomotion.

Sample size was calculated from the results of the preliminary study (G*Power Software, version 3.1.9.2; HeinrichHeine-Universität, Düsseldorf, Germany). Alpha was 0.05, and beta was 0.80 . The effect size values of BBS and locomotion of K-MBI were also calculated. Therefore, when the BBS was set as the primary outcome, 15 subjects per group were required, whereas when locomotion was set as the primary outcome, 40 subjects per group were required.

There are several points to consider when interpreting the results of this preliminary study. Our sample size was small, and our study only recruited patients with acute stroke. The assignment of patients to the two groups was not performed randomly. Thus, we recognize that a selection bias may exists. Future randomized, controlled trials are warranted.

The aim of this preliminary study was to examine the effects of virtual reality combined with balance training on upper limb function, balance, and ADL in patients with acute stroke. Both the groups showed significant improvements in MFT, BBS, K-MBI after the intervention. The experimental group showed no significant difference in MFT, BBS, and K-MBI after intervention compared to the control group. However, the experimental group showed a greater decrease in fall risk $(\mathrm{BBS}<45)$ after intervention than the control group. In conclusion, these findings suggest that virtual reality training combined with balance training may have a better effect on balance improvement than virtual reality training without balance training in acute stroke patients.

\section{Acknowledgements}

This work was supported by the National Research Foundation of Korea (NRF) grant funded by the Korea government (MSIT) (No. 2017R1C1B5075810). 


\section{Conflict of Interest}

The authors declared no potential conflicts of interest with respect to the authorship and/or publication of this article.

\section{References}

1. Kim OS, Ryu HS. The study on blood lipid levels according to the food habits and food intake patterns in Korean elderly. Korean J Food Nutr 2009;22:421-9.

2. Schmid AA, Miller KK, Van Puymbroeck M, DeBaun-Sprague E, Shively C, Peterson E, et al. Feasibility and results of a pilot study of group occupational therapy for fall risk management after stroke. Br J Occup Ther 2015;78:653-60.

3. Mackintosh SF, Hill K, Dodd KJ, Goldie P, Culham E. Falls and injury prevention should be part of every stroke rehabilitation plan. Clin Rehabil 2005;19:441-51.

4. Sveen U, Bautz-Holter E, Sødring KM, Wyller TB, Laake K. Association between impairments, self-care ability and social activities 1 year after stroke. Disabil Rehabil 1999;21:372-7.

5. Huxhold O, Li SC, Schmiedek F, Lindenberger U. Dual-tasking postural control: aging and the effects of cognitive demand in conjunction with focus of attention. Brain Res Bull 2006;69:294305.

6. Saeys W, Vereeck L, Truijen S, Lafosse C, Wuyts FP, Heyning PV. Randomized controlled trial of truncal exercises early after stroke to improve balance and mobility. Neurorehabil Neural Repair 2012;26:231-8.

7. Kang H, Chung Y. Effects of treadmill training with real optic flow scene on balance and balance self-efficacy in individuals following stroke: a pilot randomized controlled trial. Phys Ther Rehabil Sci 2012;1:33-9.

8. Pollock AS, Durward BR, Rowe PJ, Paul JP. What is balance? Clin Rehabil 2000;14:402-6.

9. Oliveira CB, Medeiros ÍR, Greters MG, Frota NA, Lucato LT, Scaff M, et al. Abnormal sensory integration affects balance control in hemiparetic patients within the first year after stroke. Clinics (Sao Paulo) 2011;66:2043-8.

10. Anderson K, Behm DG. Trunk muscle activity increases with unstable squat movements. Can J Appl Physiol 2005;30:33-45.

11. Kang TW, Kim BR. Comparison of task-oriented balance training on stable and unstable surfaces for fall risk, balance, and gait abilities of patients with stroke. J Korean Soc Phys Med 2019;14: 89-95.

12. Park JH, Chung Y. The effects of providing visual feedback and auditory stimulation using a robotic device on balance and gait abilities in persons with stroke: a pilot study. Phys Ther Rehabil Sci 2016;5:125-31.

13. Lee J, Hwang S, Ahn S. Effects of sit-to-stand imagery group training on balance performance in individuals with chronic hemiparetic stroke: a randomized control trial. Phys Ther Rehabil Sci 2016;5:63-9.

14. Bang DH, Shin WS. Effects of robot-assisted gait training on spatiotemporal gait parameters and balance in patients with chronic stroke: a randomized controlled pilot trial. NeuroRehabili- tation 2016;38:343-9.

15. Karatas M, Cetin N, Bayramoglu M, Dilek A. Trunk muscle strength in relation to balance and functional disability in unihemispheric stroke patients. Am J Phys Med Rehabil 2004;83:81-7.

16. Tankisheva E, Bogaerts A, Boonen S, Feys H, Verschueren S. Effects of intensive whole-body vibration training on muscle strength and balance in adults with chronic stroke: a randomized controlled pilot study. Arch Phys Med Rehabil 2014;95:439-46.

17. Tyson SF, Sadeghi-Demneh E, Nester CJ. The effects of transcutaneous electrical nerve stimulation on strength, proprioception, balance and mobility in people with stroke: a randomized controlled cross-over trial. Clin Rehabil 2013;27:785-91.

18. Kim JH, Jang SH, Kim CS, Jung JH, You JH. Use of virtual reality to enhance balance and ambulation in chronic stroke: a double-blind, randomized controlled study. Am J Phys Med Rehabil 2009;88:693-701.

19. Burdea GC. Virtual rehabilitation--benefits and challenges. Methods Inf Med 2003;42:519-23.

20. Reid D, Hirji T. The influence of a virtual reality leisure intervention program on the motivation of older adult stroke survivors: a pilot study. Phys Occup Ther Geriatr 2004;21:1-19.

21. Bang YS, Son KH, Kim HJ. Effects of virtual reality training using Nintendo Wii and treadmill walking exercise on balance and walking for stroke patients. J Phys Ther Sci 2016;28:3112-5.

22. Kim EJ, Ryu IT, Park HJ. Effects of virtual reality training on the balance of chronic stroke patients on an unstable surface. Neurotherapy 2018;22:7-11.

23. Chen L, Lo WL, Mao YR, Ding MH, Lin Q, Li H, et al. Effect of virtual reality on postural and balance control in patients with stroke: a systematic literature review. Biomed Res Int 2016; 2016:7309272.

24. Miyamoto S, Kondo T, Suzukamo Y, Michimata A, Izumi S. Reliability and validity of the Manual Function Test in patients with stroke. Am J Phys Med Rehabil 2009;88:247-55.

25. Riddle DL, Stratford PW. Interpreting validity indexes for diagnostic tests: an illustration using the Berg balance test. Phys Ther 1999;79:939-48.

26. Berg K, Wood-Dauphinee S, Williams JI. The Balance Scale: reliability assessment with elderly residents and patients with an acute stroke. Scand J Rehabil Med 1995;27:27-36.

27. Jung HY, Park BK, Shin HS, Kang YK, Pyun SB, Paik NJ, et al. Development of the Korean version of Modified Barthel Index (K-MBI): multi-center study for subjects with stroke. J Korean Acad Rehabil Med 2007;31:283-97.

28. Park J, Woo YK, Park SY. Effects of sit-to-stand training on unstable surface on balance in subject with stroke. Phys Ther Korea 2013;20:1-8.

29. Seo HW, Kim MC. Study on the correlation between muscle activity of lower extremity and sway speed of chronic stroke patients according to unstable surface training. J Korean Soc Integr Med 2013;1:75-83.

30. French B, Thomas L, Leathley M, Sutton C, McAdam J, Forster $\mathrm{A}$, et al. Does repetitive task training improve functional activity after stroke? A Cochrane systematic review and meta-analysis. J Rehabil Med 2010;42:9-15.

31. Lee HS, Choi JH. Correlation between BBS, FRT, STI, TUG, MBI, and falling in stroke patients. J Korean Soc Phys Ther 2008; 20:1-6. 
32. Woo HS, Park WK, Cha TH. Correlation between KoreanWMFT functional score and activities of daily living. Korean J Occup Ther 2012;20:95-104.

33. Kim JO, Lee BH. Effect of upper extremity coordination exercise during standing on the paretic side on balance, gait ability and activities of daily living in persons with stroke. Phys Ther Rehabil Sci 2017;6:53-8. 